EVS29 Symposium

Montréal, Québec, Canada, June 19-22, 2016

\title{
Capacity fade of lithium-ion batteries upon mixed calendar/cycling aging protocol
}

\author{
Sébastien Grolleau ${ }^{1}$, Issam Baghdadi ${ }^{2,3}$, Philippe Gyan ${ }^{3}$, Mohamed Ben-Marzouk ${ }^{4}$, \\ François Duclaud ${ }^{5}$

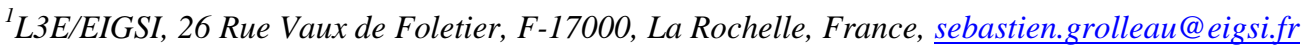 \\ ${ }^{2}$ University of Bordeaux, IMS, UMR 5218 CNRS, IPB, F-33400 Talence, France \\ ${ }^{3}$ DEA-IREB, Groupe Renault, 1 Avenue du Golf, TCR LAB 012, F-78280, Guyancourt, France \\ ${ }^{4}$ Univ. Lyon, IFSTTAR, LTE, 25 avenue François Mitterrand, F- 69675 Bron, France \\ ${ }^{5}$ EIGSICA, 47 Centre des affaires Alla Ben Abdellah Casablanca, 20000 Maroc, francois.duclaud@eigsi.fr
}

\begin{abstract}
Energy and power fade of lithium-ion batteries over time is a cause of complaints from Electric and Hybrid vehicles customers. Car manufacturers strive to improve accuracy of battery performance degradation predictions, in order to reduce warranty costs. Currently, these predictions are mainly based on accelerated aging tests in cycling mode or on calendar tests. However, testing protocols with combination of calendar and cycling modes representing the usage of a vehicle in real life application are not much used. In this paper, a mixed aging protocol combining cycling and calendar repetitive phases is elaborated. Experimental results obtained on a LIB technology are presented and discussed in comparison with conventional accelerated cycling tests at the same conditions.
\end{abstract}

Kewywords: battery calendar life, cycle life, lithium battery, reliability

\section{Introduction}

Lithium-ion battery (LIB) technology is a promising candidate for current and new generations of electric vehicles (EVs) and hybrid electric vehicles (HEVs) due to their significantly increased energetic and power densities compared to previous NiMH generations. Besides being more expensive, a major drawback of LIBs is their performances degradation over time and usage. Therefore, LIBs are nowadays substantially oversized to meet power and energy performance requirements at the end-of-life.

Aging of LIBs has been intensively studied in the literature as these vehicle applications require a long cell lifetime, typically between 5 and 10 years. In the literature, aging of LIBs is tested according to either one year calendar or accelerated cycling tests [1]-[4], serving to establish predictive aging rate based on empirical laws, which are used to extrapolate 10 years real-usage scenarios at design stage [5]-[7].

However, real automotive application differs significantly from repetitive laboratory tests in controlled environment. LIBs will experience the vehicle driving phases separated by long parking phases where the battery is either charged or unused under very variable environment conditions. Moreover, some cycle life study shows possible change in degradation mechanisms depending upon how frequently the battery is 
cycled [8], [9]. Therefore, current prediction based on accelerated cycling results could potentially overestimate life for real situations.

In order to tackle this issue, car manufacturers, suppliers and research centers have teamed their efforts into the French National collaborative program MOBICUS, whose purpose is to design and validate strategies to extend battery lifespan, depending on vehicle usage and charging patterns.

This program involves RENAULT, VALEO, EDF, SIEMENS, ERDF, as large companies, CONTROLSYS and DBT-CEV as small and medium companies, IFPEN, CEA, IFSTTAR, IMS, and EIGSI as research centers. PSA, SAFT, UTC, and LA POSTE are guest companies of this program. The program receives the financial support from BPI FRANCE, Conseil Général des Yvelines, and Conseil Régional Pas de Calais.

As part of this program, this study presents a specific aging protocol where cycling phases are interrupted by long rest period representing vehicle driving periods followed by parking phases. This aging protocol is considered by being much closer to the practical use of a LIB than conventional accelerated cycling aging tests. Influence of the last of rest periods have been explicitly taken into account by the proposed protocol. Results of these tests can be compared to more conventional accelerated storage and cycling tests in order to observe influence of alternating aging modes on cell lifetime.

\section{Experimental}

\subsection{Tested cell technologies}

Two LIB technologies dedicated to automotive application have been supplied for testing in 2014 from two different cell manufacturers. Cell nominal capacities are respectively 43 Ah (Tech \#1) and 26 Ah (Tech \#2). The cell ratings are summarized in Table 1 . The nominal discharge rate value is referred as " $\mathrm{C}$ " in the following.

Table 1: cell ratings for both tested technologies

\begin{tabular}{|l|c|c|}
\hline Parameters & $\begin{array}{c}\text { Values of } \\
\text { technology \#1 }\end{array}$ & $\begin{array}{c}\text { Values of } \\
\text { technology \#2 }\end{array}$ \\
\hline Nominal capacity at $25^{\circ} \mathrm{C}(\mathrm{Ah})$ & 43 & 26 \\
\hline End of discharge voltage, $\mathrm{U}_{\text {min }}(\mathrm{V})$ & 3.00 & 2,80 \\
\hline End of charge voltage (Floating) $(\mathrm{V})$ & 4.20 & 4.15 \\
\hline End of charge current under floating voltage $(\mathrm{A})$ & $2.2(\sim \mathrm{C} / 20)$ & $1.5(\sim \mathrm{C} / 20)$ \\
\hline
\end{tabular}

In the MOBICUS program, a wide set of tests have been performed on cells, including calendar, continuous cycling or mixed aging tests. In calendar tests, cells are disconnected and voltage is not maintained. Modules are made out of three cells in series for reproducibility. Three cells are submitted to similar conditions, and the performance degradation of each one is measured during Reference Performance Tests (RPTs) presented in details in 2.3. In continuous cycling tests, cycling is interrupted only to perform RPTs. In mixed aging tests, cells are submitted to alternating cycling and rest periods which durations are defined in Erreur ! Source du renvoi introuvable..

Regarding continuous cycling and mixed aging tests, three series connected cells of the same technology are assigned to a specific aging test allowing using only one test channel for cycling three distinct cells at the same condition. Surface temperature of each cell is monitored and a thermal management is applied to keep the temperature difference between the cells surface and ambient below $10^{\circ} \mathrm{C}$ maximum.

Aging tests have been shared amongst all the experimenters of the MOBICUS program which are presented on Figure 1. 


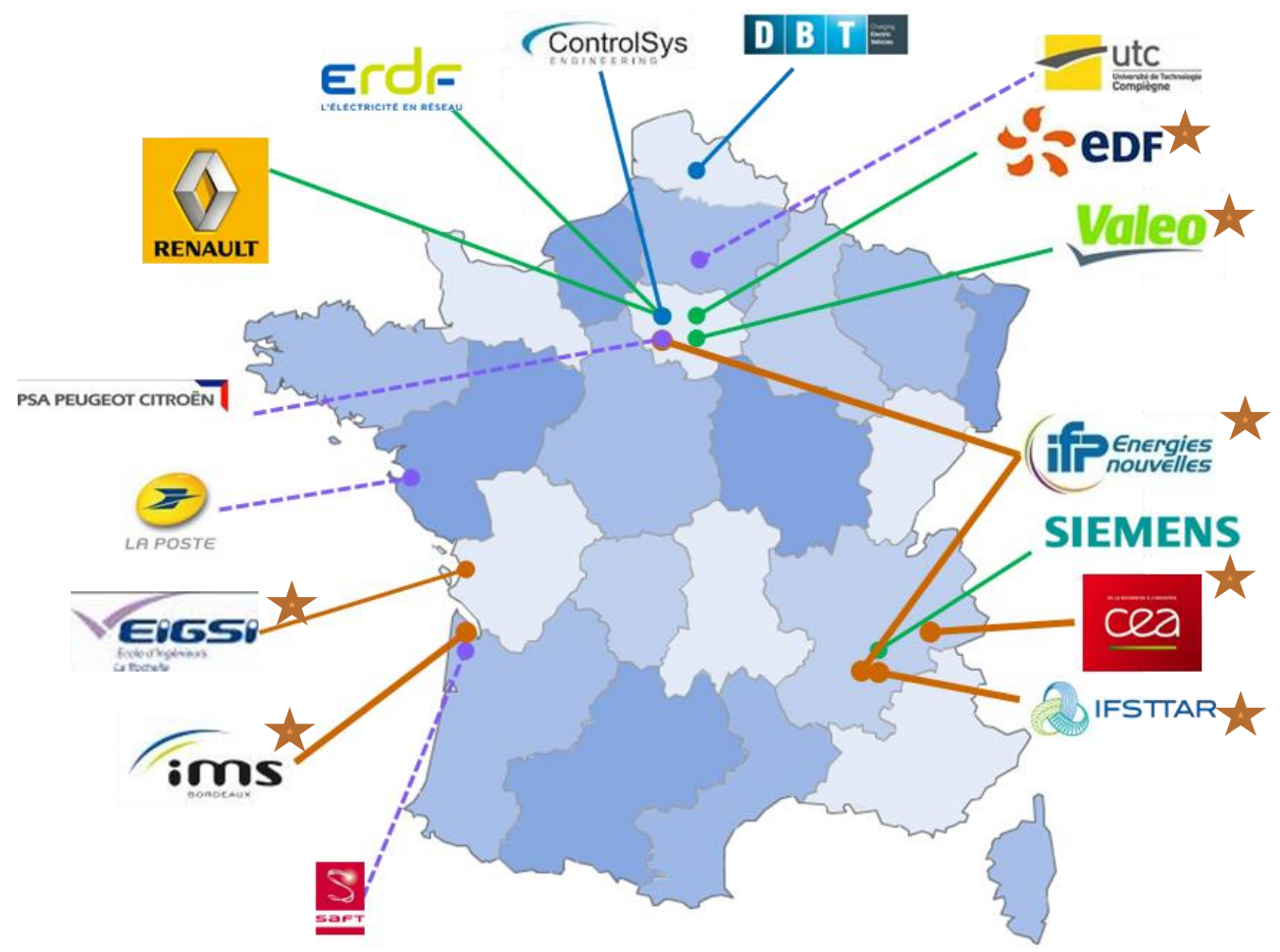

Figure 1 : Members of the MOBICUS program. Experimenters sharing aging tests are highlighted using 4 . Renault is the program leader.

\subsection{Calendar and continuous cycling aging protocol}

\subsubsection{Calendar tests}

Amongst the different calendar tests, storage on fixed SoC and fixed temperature for both cell technologies have been started in March 2015 and shared by the MOBICUS experimenters.

Modules of three cells have been allocated to the different test conditions presented in the calendar test matrix presented in Table 2. These tests are distributed in 4 different temperatures $\left(0,25,45\right.$ and $\left.60^{\circ} \mathrm{C}\right)$ and 5 different SoCs $(0,30,65,80$ and 100\%). For cell technology \#1, 10 storage tests have been carried out, whereas a more complete test has been planned for cell technology \#2 (16 tests).

Table 2: calendar test matrix and cell allocations for both technologies

\begin{tabular}{|l|c|c|c|c|c|}
\hline & SoC $=100 \%$ & SoC $=80 \%$ & SoC $=65 \%$ & SoC $=30 \%$ & SoC=0\% \\
\hline Temp. $60^{\circ} \mathrm{C}$ & $\# 2$ & $\# 1, \# 2$ & $\# 2$ & $\# 2$ & \\
\hline Temp. $45^{\circ} \mathrm{C}$ & $\# 1, \# 2$ & $\# 1, \# 2$ & $\# 1, \# 2$ & $\# 1, \# 2$ & $\# 1, \# 2$ \\
\hline Temp. $25^{\circ} \mathrm{C}$ & $\# 2$ & $\# 1, \# 2$ & $\# 2$ & $\# 2$ & \\
\hline Temp. $0^{\circ} \mathrm{C}$ & $\# 2$ & $\# 1, \# 2$ & & $\# 1, \# 2$ & \\
\hline
\end{tabular}

\#1: Cell techno \#1, \#2: Cell techno \#2

\subsubsection{Continuous cycling tests}

Furthermore, the vast experimental plan of the MOBICUS project contains accelerated cycling tests at different values of SoC. Influence of aging factors such as ambient temperature (3 values), SoC (4 values), charge current ( 2 values) and discharge current ( 2 values) are being investigated. Cycling is performed 
around a mean $\mathrm{SoC}$ value in a $+/-5 \%$ SoC window. It is interrupted only during Reference Performance Tests.

A full factorial design of experiments (DoE) for these selected aging factors would have required 48 tests for each cell technology. Taking into account the available equipment for MOBICUS project, only 17 tests for each technology have been realized. A D-optimal design is thus chosen to answer these conditions, and the obtained DoE is decomposed on 3 test batches to be most adaptive as possible.

In this paper, we will focus only on results obtained at maximum charging current and discharge currents at $25^{\circ} \mathrm{C}$ and $45^{\circ} \mathrm{C}$ as they correspond to the same rates than those used for mixed aging tests. A detailed study of results of the cycling tests is carried out in a distinct dedicated paper [10].

Table 3: experimental plan of "continuous" cycling tests divided into three test batches and their status

\begin{tabular}{|c|c|c|c|c|}
\hline \multicolumn{5}{|c|}{ Test batch 1 (finished) } \\
\hline Test & Temperature & SoC & I charge & I discharge \\
\hline 1 & 0 & 30 & MAX & min \\
\hline 2 & 0 & 80 & min & MAX \\
\hline $\mathbf{3}$ & $\mathbf{0}$ & $\mathbf{8 0}$ & MAX & MAX \\
\hline 4 & 25 & 30 & $\min$ & MAX \\
\hline 5 & 25 & 30 & MAX & min \\
\hline 6 & 25 & 80 & MAX & min \\
\hline 7 & 45 & 30 & min & min \\
\hline $\mathbf{8}$ & $\mathbf{4 5}$ & $\mathbf{3 0}$ & MAX & MAX \\
\hline 9 & 45 & 80 & min & MAX \\
\hline
\end{tabular}

\begin{tabular}{|c|c|c|c|c|}
\hline \multicolumn{5}{|c|}{ Test batch 2 (on-going) } \\
\hline Test & Temperature & SoC & I charge & I discharge \\
\hline 10 & 0 & 90 & min & min \\
\hline 11 & 25 & 65 & min & min \\
\hline 12 & $\mathbf{2 5}$ & $\mathbf{6 5}$ & MAX & MAX \\
\hline 13 & $\mathbf{4 5}$ & $\mathbf{6 5}$ & MAX & MAX \\
\hline
\end{tabular}

\begin{tabular}{|c|c|c|c|c|}
\hline \multicolumn{5}{|c|}{ Test batch 3 (planned) } \\
\hline Test & Temperature & SoC & I charge & I discharge \\
\hline 14 & 0 & 65 & min & MAX \\
\hline 15 & 25 & 90 & min & MAX \\
\hline 16 & 45 & 90 & MAX & MAX \\
\hline 17 & 45 & 90 & min & MAX \\
\hline
\end{tabular}

\subsubsection{Mixed calendar and cycling aging protocol}

The mixed aging test protocol consists in a 12 hours aging basic pattern which is divided into a calendar part and a cycling part (Figure 2). The two investigated patterns differ only by the repartition of the aging parts: in the first pattern, the cycling part lasts only 2 hours over the 12 hours of the pattern (pattern $=2 / 12$ ) whereas it last 6 hours for the second one (pattern $=6 / 12$ ), meaning that the cell spends equal time in cycling and storage mode.

These specific tests have been shared between L3E (EIGSI) and IMS (Bordeaux University).

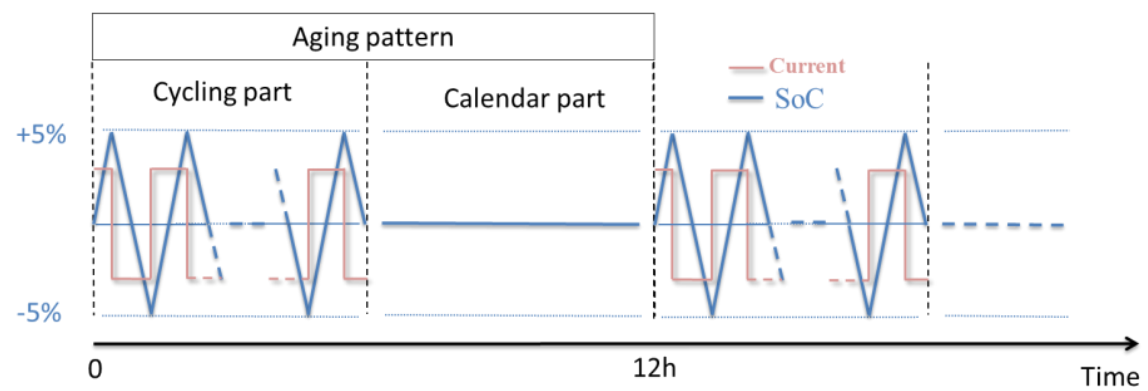

Figure 2: repeated basic aging pattern divided in a cycling part $(\mathrm{I} \neq 0)$ and a calendar part $(\mathrm{I}=0)$

Table 4 : experimental plan of mixed aging protocol for the two tested cell technologies

\begin{tabular}{|c|c|c|c|}
$\begin{array}{c}\text { Ambient } \\
\text { temperature }\end{array}$ & $\begin{array}{c}\text { Fraction of } \\
\text { cycling time } \\
\text { in aging } \\
\text { pattern }\end{array}$ & SoC (\%) & $\begin{array}{c}\text { Charging \& } \\
\text { discharge } \\
\text { current }\end{array}$ \\
\hline $25^{\circ} \mathrm{C}$ & $2 / 12$ & 80 & \\
\hline & $2 / 12$ & 65 & 1C (Tech \#1) \\
\hline $45^{\circ} \mathrm{C}$ & $6 / 12$ & 65 & 3C (Tech \#2) \\
& $2 / 12$ & 80 & \\
\hline & $2 / 12$ & 65 & \\
\hline & $6 / 12$ & 65 & \\
\hline
\end{tabular}


During the cycling phases, cells are successively discharged and charged at constant current without relaxation around a specified $\mathrm{SoC}$ according to a simple temporal profile presented on Figure 2. Ambient temperature is maintained constant whichever the part of the aging pattern.

Influences of aging factors such as the ambient temperature $\left(25^{\circ} \mathrm{C}\right.$ and $\left.45^{\circ} \mathrm{C}\right)$ and $\mathrm{SoC}(65 \%$ and $80 \%)$ have been investigated as summarized by Table 2 for the two tested cell technologies. Choice of current value has been made in agreement with cell application (respectively EV for tech \#1 and Plugin HEV for tech \#2). Three cells of each technology are tested as a series module for each condition of the testing plan shown on Table 2, representing 18 tested cells per technology.

\subsubsection{Technical implementation of the mixed aging protocol}

The choice of the patterns enables to use only one test channel to test three distinct modules. Indeed, as shown in Figure 3, cycling phases of the three modules do not overlap each other if two of them are tested according to the aging pattern 2/12 (cycling only 2 hours over 12) whereas a third module is submitted to the second aging pattern 6/12 (cycling 6 hours over 12).

Therefore, a specific multiplexing system using command and power relays were specifically designed to disconnect automatically modules entering in the calendar phase and connect the module entering in the cycling phase to the channel. The multiplexing switch is directly managed by the cycling program in the test channel as illustrated on Figure 4. Surface temperature and voltage of all cells of the three modules are monitored and recorded during tests regardless of the aging mode (cycling or calendar).

\begin{tabular}{|c|c|c|c|c|c|c|c|c|c|c|c|c|c|}
\hline Pattern & Module & & & & & & & & & & & & \\
\hline $2 / 12$ & Module 1 & & Cycling & & & & & & alendar & & & & \\
\hline $2 / 12$ & Module 2 & & & & Cycling & & & & & \multicolumn{2}{|l|}{ Calendar } & & \\
\hline \multirow[t]{2}{*}{$6 / 12$} & Module 3 & & & Calendar & & & & & & Cyclin & & & \\
\hline & Hours & 0 & 1 & 2 & 3 & 4 & 5 & 6 & 7 & 8 & 9 & 10 & 11 \\
\hline
\end{tabular}

Figure 3 : time schedule highlighting cycling and calendar phases of 3 cell modules connected to a single test channel

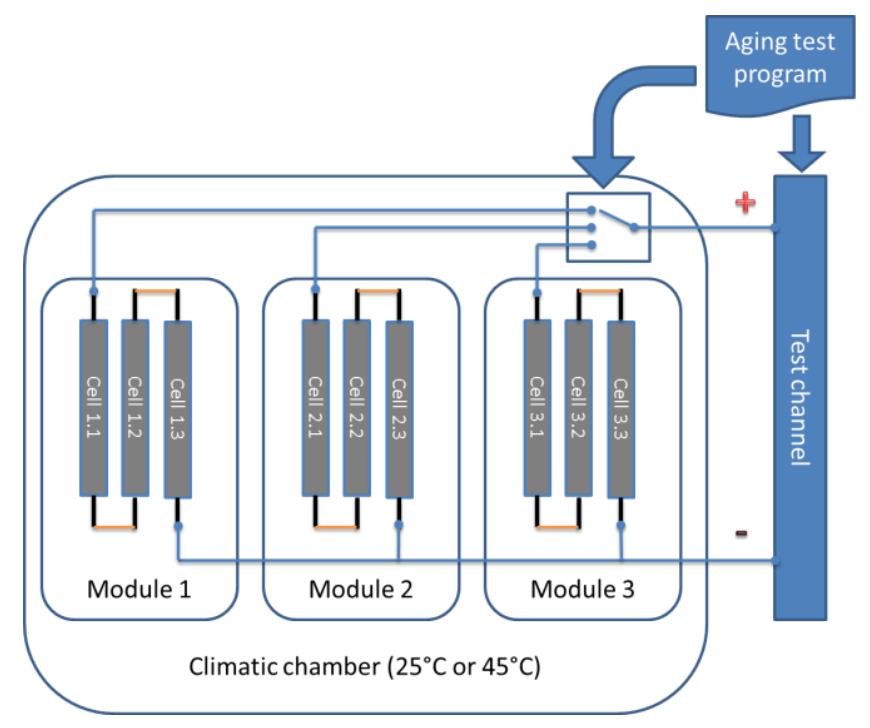

Figure 4 : Schematic representation of the multiplex system used to test 3 modules on a single test channel

\subsection{Reference performance test}

Periodically, cells of each module are taken individually and their performances are tested according to a Reference Performance Test (RPT). Capacities for each cell are measured using a CCCV discharge C/10 rate until $\mathrm{U}_{\min }$ defined in Table 1 . The choice of low $\mathrm{C}$-rates enables to realise incremental capacity analysis on cells at different state-of-health. 
Then, cells are reconnected in modules and fully charged. Cell resistance is then characterized using current pulses at every $15 \%$ SoCs for two values of current both in charge and discharge mode. Open Circuit Voltage of cells is also recorded at the end of pauses of 45 minutes between pulses. RPT are systematically performed at $25^{\circ} \mathrm{C}$ which serves a reference temperature for both cell technologies every 6 weeks for continuous cycling, every 8 weeks for mixed aging tests and every 12 weeks for calendar tests. For some test conditions, additional RPTs are conducted at 2 other temperatures, $10^{\circ} \mathrm{C}$ and $45^{\circ} \mathrm{C}$, at the beginning and at the end of the aging tests.

Figure 5 presents capacity and discharge resistance evolutions for the two cell technologies measured during the first RPT with tested temperatures. Resistances are obtained from cell voltage evolution after 10 seconds during a $\mathrm{C} / 2$ discharge pulse at $\mathrm{SoC}=100 \%$.
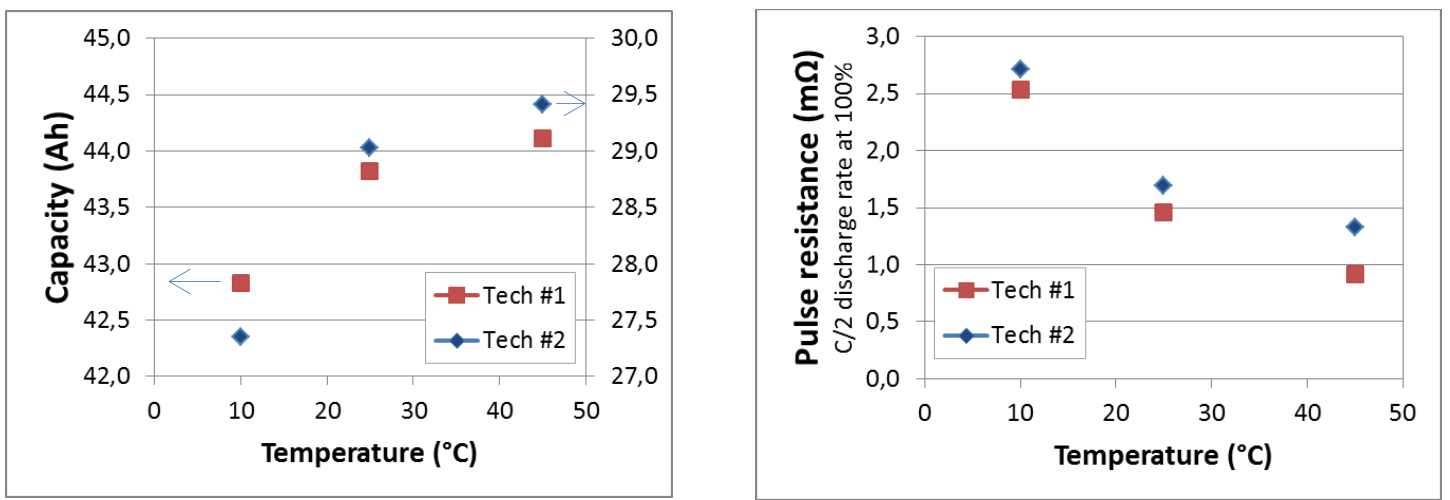

Figure 5 : capacity and resistance evolution with temperature for the two tested LIB technologies at fresh state

\section{Preliminary aging results and analyses}

\subsection{Calendar and continuous cycling aging tests}

This part presents aging results from calendar and accelerated cycling obtained for Tech. \#1. Capacity retentions of continuous cycling at $1 \mathrm{C} / 1 \mathrm{C}$ at $0^{\circ} \mathrm{C}, 25^{\circ} \mathrm{C}$ and $45^{\circ} \mathrm{C}$ are compared with results of calendar aging tests at similar test conditions (except for $\mathrm{T}=25^{\circ} \mathrm{C}$ where the $\mathrm{SoC}$ is slightly different) on Figure 6 . 


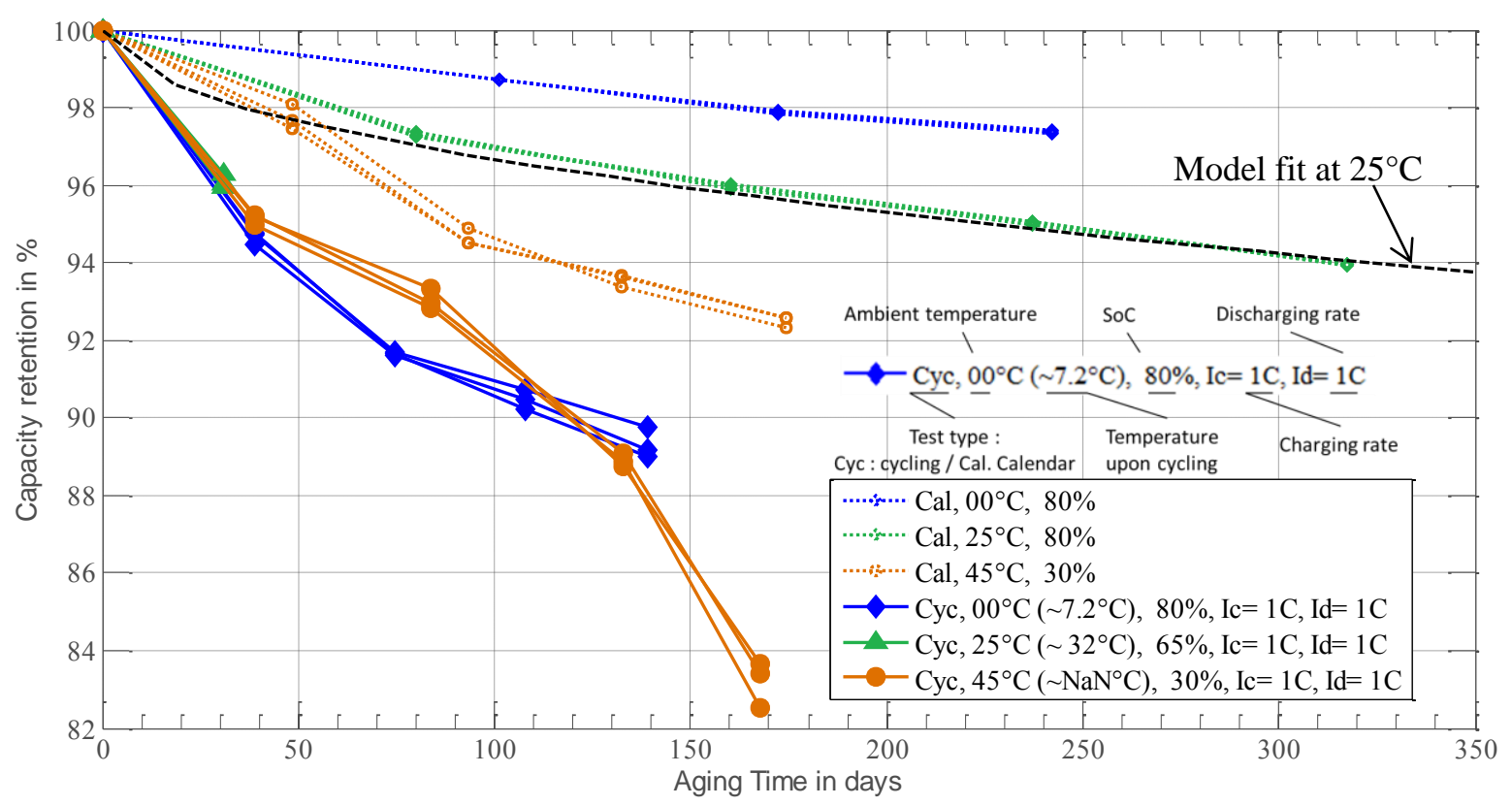

Figure 6 : capacity degradation versus aging time measured according to the calendar and "continuous" cycling aging protocol defined in 2.2. A model fit for calendar data at $25^{\circ} \mathrm{C}$ is also shown.

Predicting capacity loss requires a correct separation between calendar and cycling aging mechanisms.This graph allows estimating how the cycling affects global aging of cell by comparing them to data from cells stored in similar temperature and SoC conditions (calendar cells).

For all tested temperatures, impact of continuous cycling on aging is very significant at the presented Crates on tech \#1 Impact of continuous cycling is the most severe at $0^{\circ} \mathrm{C}$ as cycled cells experienced a sharp capacity loss and as the calendar aging is the most limited at this temperature. At $45^{\circ} \mathrm{C}$, a very significant part of the global aging of continuous cycling can be attributed to the calendar aging. After 165 days of aging at $45^{\circ} \mathrm{C}$, results suggest that calendar aging may be responsible of about the half of the measured capacity loss on continuous cycling.

Previous studies demonstrated that the main mechanism of LIBs in storage mode was growth of the Solid Electrolyte Interphase (SEI) on negative electrode which evolution follows classically a $\sqrt{t}$ time dependency [1], [3], [11]. Here, a simple model for the relative capacity loss in $\% Q_{\text {loss, cal }}$ has been derived from calendar aging data at $25^{\circ} \mathrm{C}$ using least-squares regression and will be used in the following of this document. In this paper, SoC dependence of $Q_{\text {loss }, \text { cal }}$ at $25^{\circ} \mathrm{C}$ has been neglected.

$$
Q_{\text {loss }, \text { cal }}\left(25^{\circ} \mathrm{C}, t\right)=k_{\text {cal }} \cdot \sqrt{t} \approx 0.333 \cdot \sqrt{t}
$$

\subsection{Mixed calendar and cycling aging tests}

So far, only preliminary results at $25^{\circ} \mathrm{C}$ of the mixed aging protocol presented in Erreur ! Source du renvoi introuvable. on cell technology \#1 were obtained at the time of writing this paper. All cells experienced approximately the same aging time but the number of microcycles depends on the aging protocol: naturally, cells submitted to continuously cycling achieved the highest number of microcycles and the highest Ah Throughput (cumulated discharged Ah) even if their aging time is the smallest. These aging results are then compared with results of calendar aging conditions and on Figure 7. Influence of aging pattern of mixed aging protocol $(2 \mathrm{~h} / 12 \mathrm{~h})$ and $(6 \mathrm{~h} / 12 \mathrm{~h})$ can be therefore estimated. Comparison of cell surface temperature evolutions have revealed a very small difference of surface temperature upon cycling whichever cells are submitted to continuous or mixed aging test for the presented tests.

As expected, cells cycling 6 hours over 12 (half time) deteriorate more rapidly than cells cycling only 2 hours. However, there is only a tiny difference in measured degradation rates (capacity loss versus aging time) between cells cycled half time and those submitted to continuous cycling for similar conditions after 
about 40 days of cycling. Furthermore, preliminary results suggest that cells cycling only 2 hours over 12 around $\mathrm{SoC}=80 \%$ deteriorate faster than cells stored at $25^{\circ} \mathrm{C}$ at $\mathrm{SoC}=65 \%$.
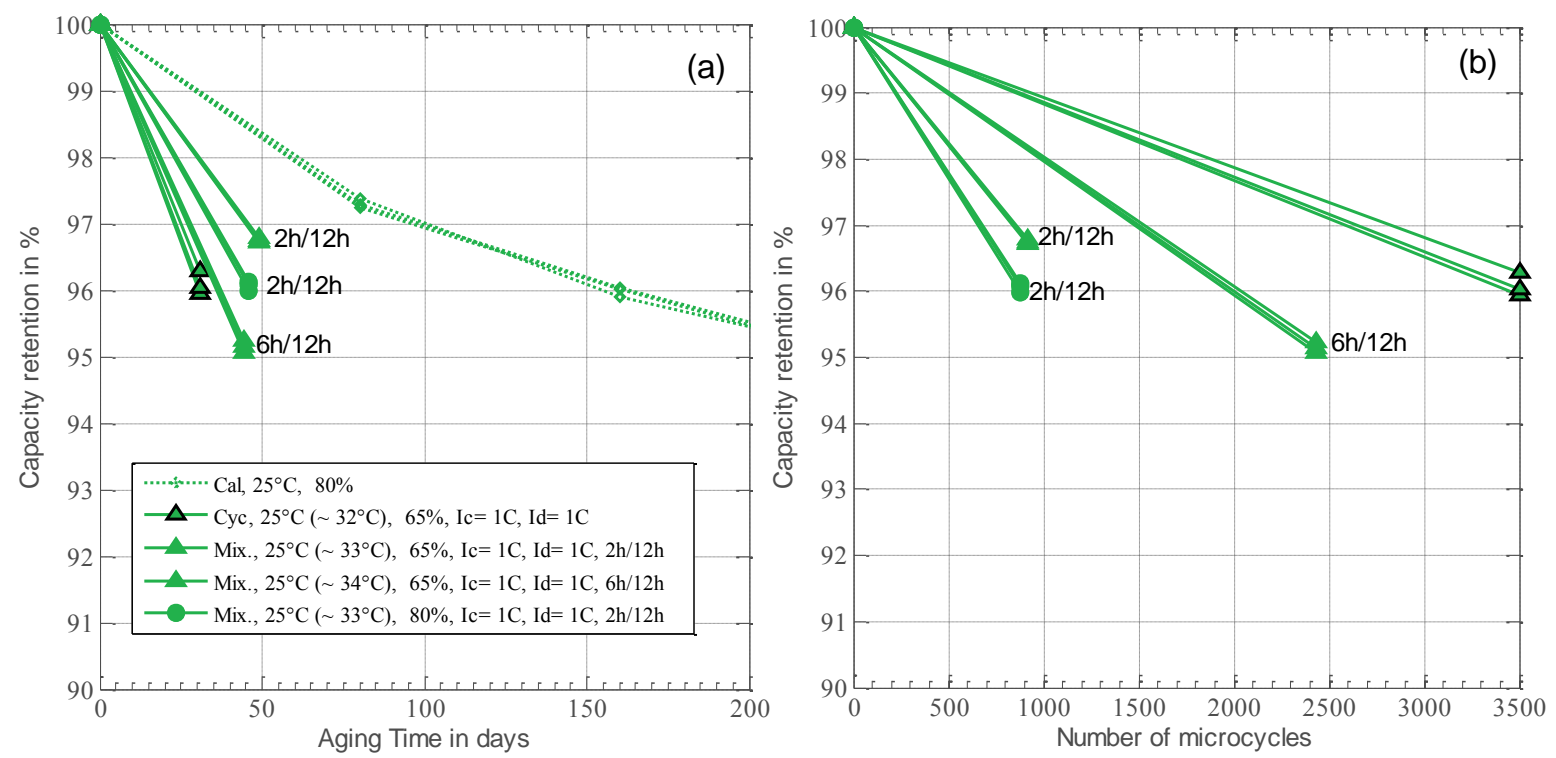

Figure 7: capacity degradation for calendar (Cal.), continuous cycling (Cyc.) and mixed aging patterns (Mix.) at $25^{\circ} \mathrm{C}$ for cell technology \#1 versus aging time (a) and cycling number (b)

Table 5 summarizes the aging results of the different cycling conditions at $25^{\circ} \mathrm{C}$ obtained at the time of writing this paper. According to their respective aging time, an equivalent loss of capacity due to calendar aging $Q_{\text {loss,cal }}$ has been derived for each cycling condition using Eq. (1). As a first approach, the degradation induced by cycling $Q_{l o s, c y c}$ is then approximated by subtracting the estimated calendar part to the measured capacity loss of the cells.

Table 5: summary of aging results for cell technology \#1 for mixed protocol and continuous cycling at $25^{\circ} \mathrm{C}$

\begin{tabular}{|c|c|c|c|c|c|c|}
\hline Aging protocol & $\begin{array}{c}\text { Aging time } \\
\text { (days) }\end{array}$ & $\begin{array}{c}\text { Accomplished } \\
\text { number of } \\
\text { cycling }\end{array}$ & $\begin{array}{c}\text { Cumulated } \\
\text { Ah } \\
\text { throughput } \\
\text { (Ah) }\end{array}$ & $\begin{array}{c}\text { Experimental } \\
Q_{\text {loss }}(\%) \\
\text { (Average value } \\
\text { on the 3 cells) }\end{array}$ & $\begin{array}{c}\text { Predicted } Q_{\text {loss, cal }} \text { by } \\
\text { Eq. (1) } \%) \\
\text { "calendar loss" }\end{array}$ & $\begin{array}{c}Q_{\text {loss,cyc }}=Q_{\text {loss }}- \\
Q_{\text {loss, }, \text { cal }}(\%) \\
\text { "cycling loss" }\end{array}$ \\
\hline $\begin{array}{c}\text { SoC=65\%, } \\
\text { Mixed 2h/12h }\end{array}$ & 49 & 920 & 4154 & 3.30 & 2.33 & 0.97 \\
\hline $\begin{array}{c}\text { SoC=65\%, } \\
\text { Mixed 6h/12h }\end{array}$ & 44 & 2435 & 10651 & 4.92 & 2.22 & 2.70 \\
\hline $\begin{array}{c}\text { SoC=80\%, } \\
\text { Mixed 2h/12h }\end{array}$ & 46 & 880 & 3973 & 3.99 & 2.25 & 1.74 \\
\hline $\begin{array}{c}\text { SoC=65\% } \\
\text { Continous } \\
\text { cycling }\end{array}$ & 31 & 3500 & 15257 & 3.91 & 1.85 & 2.06 \\
\hline
\end{tabular}

\subsection{Degradation rates upon cycling}

The aging protocol enables to study how degradation of cells is affected by the frequency at which the battery is cycled. In the present case, depending on the cycling protocol cell are cycled 2 over 12 hours, 6 over 12 hours or cycled continuously at same ambient temperature $\left(25^{\circ} \mathrm{C}\right)$ and cycling C-rate (1C). 
The bar graph shown in Figure 8 (a) presents the repartitions of capacity loss between calendar and cycling losses for each test conditions reported in Table 5. Capacity loss induced by cycling is then used to estimate the capacity loss degradation rate according to the number of microcycles accomplished by the cells which is plotted on Figure 8 (b) for every cycling condition.

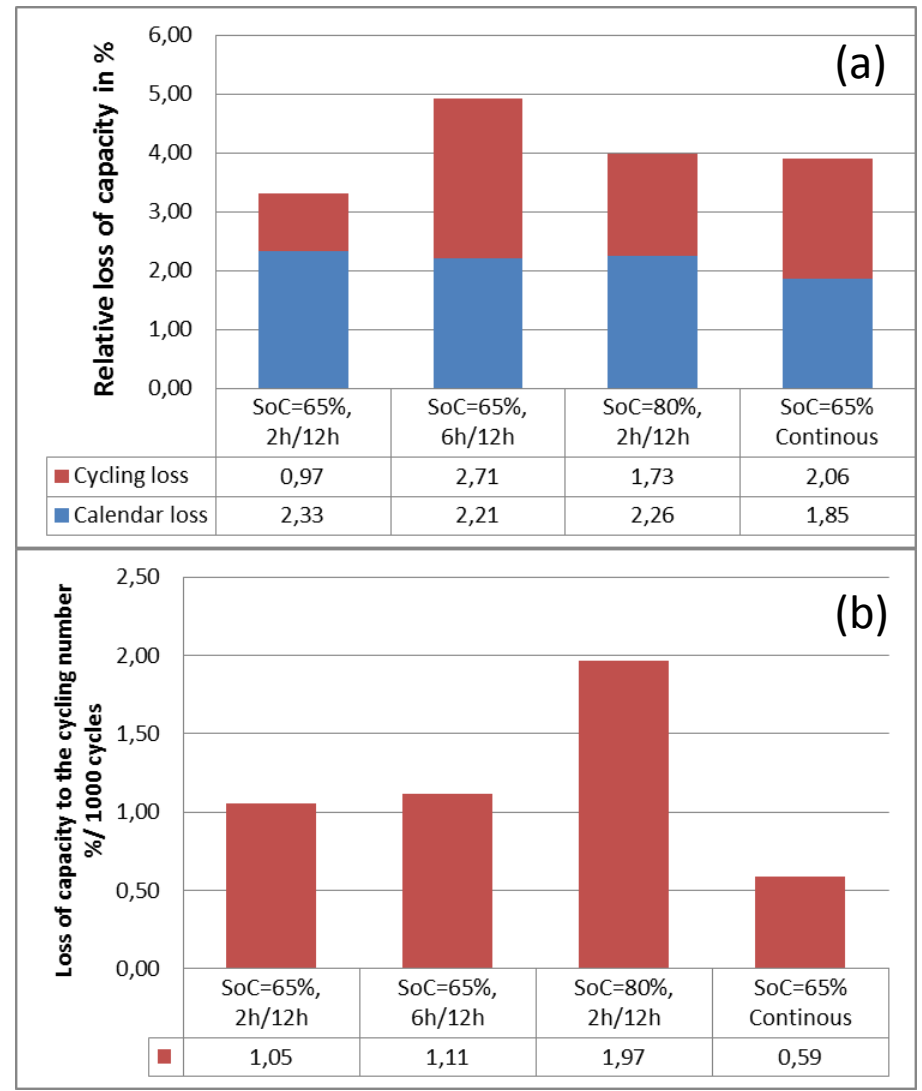

Figure 8: repartition between estimated calendar and cycling loss (a) and derived degradation rates upon cycling (b) for mixed and continuous cycling conditions at $25^{\circ} \mathrm{C}$ for cell technology \#1

Figure 8 (b) shows that degradation rate of cells is significantly affected by the cycling protocol for presented aging tests. At same temperature and C-rate conditions, cycling the cells either 2 hours or 6 hours over 12 hours does not modify the degradation rate due to cycling. In our case, cells lose about $1.1 \%$ capacity per 1000 microcycles (+/- 5\% SoC) when they are used either 2 hours or 6 hours over 12 hours at same C-rates, SoC levels and ambient temperature. The calculated degradation rates for the continuous cycling condition is however $40 \%$ lower than for other tests which tends to indicate that accelerated cycling leads to temper significantly the degradation rate and confirm previously presented results showing that degradation rate depends on how frequent LIBs are used [8], [9].

Furthermore, results suggest also that SoC of cycling has a significant influence on the capacity degradation induced by cycling for the considered cell technology. At same temperature, same C-rates and same cycling frequency, increasing only the $\mathrm{SoC}$ of cycling from $60 \%$ to $80 \%$ and contributes to almost double the degradation rate due to cycling at $25^{\circ} \mathrm{C}$.

These results have been established on the basis of ongoing aging results and must be confirmed by future measurements at same conditions. Moreover, results of similar aging protocol but performed on LIB tech \#2 will permit to consolidate or not present conclusions.

\section{Conclusion}

In a real automotive application, LIBs are submitted to a complex usage mixing calendar and cycling aging modes. Nevertheless, aging of LIBs is rarely tested according to such a mixed usage. As a consequence, aging predictive models are in the most cases built from calendar aging data on the first hand and accelerated cycling data on the other hand but there is still a lack of validation of these models according to complex usages. This paper tackles this issue by presenting two aging patterns that combine both calendar and cycling aging modes but differs in the repartition of the two modes. Two recent LIB technologies 
dedicated to automotive application are tested according to an experimental plan investigating influences of ambient temperature and SoC and how frequent the battery is cycled.

Analysis of degradation upon cycling has been conducted by subtracting the part attributable to calendar aging at $25^{\circ} \mathrm{C}$ before deriving the cell capacity degradation rate (capacity loss versus cycling number) for each cycling test. By comparison with results obtained from a conventional $1 \mathrm{C} / 1 \mathrm{C}$ continuous cycling aging test, analysis of preliminary results of mixed aging patterns tends to indicate that degradation rate is significantly affected by the aging pattern and therefore by the frequency of cycling. Accelerated cycling leads to temper significantly degradation rate due to cycling in comparison with more realistic aging pattern of automotive application where cells are cycled only 2 hours over 12 . As a consequence, current prediction based on accelerated cycling results may potentially over-estimate life for real situations. Future results of similar aging protocol but performed on a different LIB technology will permit to generalise or not present conclusions.

\section{Acknowledgments}

We acknowledge all members of the MOBICUS program for fruitful discussions and contributions. This program received financial support from BPI France, the Conseil Général des Yvelines and the Conseil Régional du Nord Pas De Calais.

\section{References}

[1] A. Delaille et al., Simcal Project: Calendar Aging Results Obtained On a Panel of 6 Commercial LiIon Cells, 224th ECS Meeting, 2013.

[2] W. Liu et al., Study of graphite/NCA Li-ion cell degradation during accelerated aging tests - Data analysis of the SIMSTOCK project, Vehicle Power and Propulsion Conference (VPPC).

[3] J. Belt et al., Calendar and PHEV cycle life aging of high-energy, lithium-ion cells containing blended spinel and layered-oxide cathodes, Journal of Power Sources, ISSN 0378-7753, 23(2011), 1021310221

[4] F. Badin, Modelling of On-board Energy Storage System ageing - The French SIMSTOCK research network, EVS24, 2009.

[5] P. Gyan et al., Experimental Assessment of Battery Cycle Life Within the SIMSTOCK Research Program, Oil \& Gas Science Technologies, ISSN 1294-4475, 68(2013), 137-147.

[6] M. Ecker et al., Development of a lifetime prediction model for lithium-ion batteries based on extended accelerated aging test data, Journal of Power Sources, ISSN 0378-7753, 215(2012), 248-257.

[7] J. Wang et al., Cycle-life model for graphite-LiFePO4 cells, Journal of Power Sources, ISSN 03787753, 196(2011), 3942-3948.

[8] J. Hall et al., Decay Processes and Life Predictions for Lithium Ion Satellite Cells, International Energy Conversion Engineering Conference (IECEC), 2006.

[9] K. Smith et al., Design of Electric Drive Vehicle Batteries for Long Life and Low Cost, Workshop on Accelerated Stress Testing and Reliability, 2010.

[10] M. Ben Marzouk et al., Experimental protocols and first results of calendar and/or cycling aging study of lithium-ion batteries - the MOBICUS project, EVS29, 2016.

[11] M. Kassem et al., Calendar aging of a graphite/LiFePO4 cell, Journal of Power Sources, ISSN 03787753, 208(2012), 296-305. 


\section{Authors}

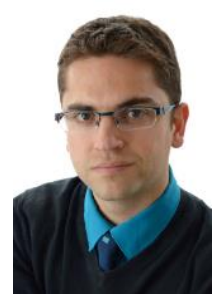

Dr. Sébastien Grolleau received his PhD from University Caen Basse-Normandie in 2013; his subject thesis was the ageing study and modelling of high power lithium-ion technologies with a special focus on aging due to storage. Since 2014, he joined the Engineer School EIGSI as a research engineer and works on national and international research projects focused on aging of lithium-ion batteries.

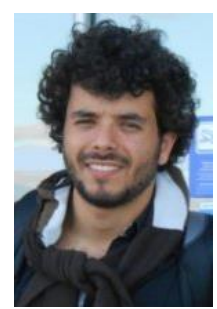

Ing. Issam Baghdadi received his MSc in electrochemistry and process from Grenoble Institute of Technology in 2014. He joined the Renault group and IMS laboratory since September 2014 as a $\mathrm{PhD}$ student in electronics at University of Bordeaux. His PhD subject is about experimental study and modelling of lithium batteries with a special focus on aging due to power cycling and storage. $\mathrm{He}$ is involved on the French National project MOBICUS as an experimenter.

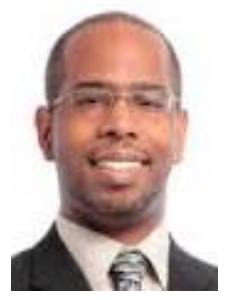

Dr. Philippe Gyan graduated from the Ecole Centrale de Lyon with a Master of Science in 1998, and with a Ph.D in 2003, in Mechanical Engineering, Energy and Thermal Management. Since 2008, he has been working in the Research Department at Renault, on powertrain sizing for Electric Vehicles, on battery electrical, thermal, and ageing modelling, and on the consideration of climate and environment conditions in energy consumption and vehicle range calculation. He was involved in the French national collaborative projects SIMSTOCK and SIMCAL, on battery ageing modelling, and is author of several publications.

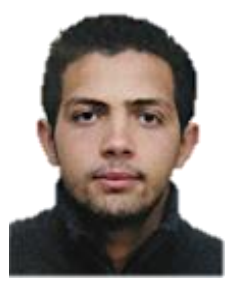

Mohamed Ben Marzouk received his master degree in 2013 which was on collaboration between Ecole Centrale de Lyon, INSA Lyon and Université Claude Bernard. Since September 2014, He is working on the MOBICUS project in IFSTTAR. He is employed as an engineer in scientific instrumentation within the VEH team (hybrid and electric vehicles) of the LTE lab (Transport and Environment Laboratory). 